\title{
Look Towards To New Technology Develop New Models Of Learning And Teaching Method- Tablet Could Change The Educational System?
}

\author{
N. Pankaja \\ Research Scholar Electronic Media Educational Media Research Center (EMRC) University of Mysore. \\ Mysore, Karnataka State, India.
}

\begin{abstract}
The paper highlights the efficiency of new technology in education. The Impact of New technology in ICT (Information \& Communication Technologies) can help the students, researchers and academicians to access the full text from the electronic sources. Today the e-publishing and e-learning modules or resources carry out the educational functions efficiently and effectively. So the modern education system may change the way of learning with the help of mobile technologies. So the present paper finding is perceived on the importance and its satisfactory level towards the future technology (tablet) and learning system in the future education.
\end{abstract}

Key Words: ICT (Information Communication Technologies), PDA (Personal Digital Assistant),

\section{Introduction}

Learning with, for instance, mobile game technologies can indeed make learning more pleasant and more effective. Future intelligent environments also described as Ubiquitous Computing or Ambient. A key objective of learning will be to obtain and create knowledge at the right time, in the right place, in the right way, on the right device and available for everyone. There will be embedded learning processes for all ages - from the cradle to the grave - for example, intelligent toys for the first few years of life, game-based learning in preschool and social collaboration and filtering tools in kindergartens. Communication will be increased in communities such as high schools, where prime tools will be personalized digital libraries in project-based learning with immediate access to the Internet, and with ubiquitous student controlled interfaces.

Internet has gained popularity in finding any kind of information on any branch of knowledge. The information technology sector has slowly taken advantage of this shift from a paper-based source to electronic media due to the rapid and strong impact of Information Communication Technologies (ICT) available to create host and access full text electronic information resources. The e-publishing and e-learning modules or resources carry out the educational functions efficiently and effectively (Dali, 2008). A number of tools and techniques were developed since, earlier, technology use to collected non-books materials such as video cassettes, audio cassettes, micro card, micro film and micro fitch etc. (Rarnaiah, 1998) and call them multimedia collection, however, each one of these forms of documents needed special equipment in order to use them.

\section{Transitions of ICT technology- From stand-alone system to tablet}

There was no single platform on which all these forms of information could be stored for retrieval. During 1980's computer spellings succeeded by integrating text, graphics, animation audio and video information on a computer after converting then inter digital format called multimedia. The way in which faculty, research scholars and students learn and the method of teaching will change completely over the next few years (Westwood, 2008).

(Encyclopedia Britannica, 2006): The first innovation of publishing and learning revolutionary was started from 888 (A.D) Block Printing, 1041(A.D) Invented movable clay type, 1423 (A.D) Xylography , 1436 (A.D) Printing press, 1440 (A.D) Movable metal type, 1450(A.D) First are 40 lines per page, 1455 (A.D) First block-printed Bible ,1457 (A.D) first known color printing by Faust, 1461 (A.D) Printed the first illustrated book, 1476 (A.D) First use of copper engravings instead of woodcuts for illustration and 1884 (A.D) Typewriter (Ament, 1997-2007) were introduced in the commercial market which had on everlasting impact on publishing.

Invention of printing technology in second half of the 15th century started a revolution of in spreading thoughts and scholarships. Later on microfilm (1839), Sound Recording discs (1877), Audio Tapes (1899), Video Tape and Television (1908), Micro Computers (1980), CD-ROM (1985), Optical Storage Device (1985) (Schreiner, 2008) and DVD (1997-98) etc. were introduced in the commercial market which had on everlasting impact on publishing (Pratap Singh, 2004). 


\section{$20^{\text {th }}$ century and new technology:}

Early examples of the information tablet concept originated in the 20th century mainly as prototypes and concept ideas; prominently, Alan Kay's Dynabook of 1968. The first commercial portable electronic devices based on the concept appeared at the end of the 20th century. During the 2000s Microsoft attempted a relatively unsuccessful product line with Microsoft Tablet PC, which carved a niche market at hospitals and outdoor businesses. In 2010, Apple released the iPad, which used the operating system and touch screen technology similar to that used in their iPhone and became the first mobile computer tablet to achieve worldwide commercial success. This has sparked a new market for tablet computers and a variety of other manufacturers have produced versions of their own including Samsung, HTC, Motorola, RIM, Sony, Amazon, HP, Microsoft, Archos and many others. Competing tablets use a variety of operating systems, although the main contenders are iOS (Apple), Android (Google), Windows (Microsoft) and QNX (RIM).

\section{1st century \& Tablet}

Concept of tablet is one of the important information technologies in the 21 st century. It is not a new technology but it offers a new and exciting way of using computer technology. There are rapid developments in data processing in the 1970's. The thrust was on text processing in the 1980's and now the emphasis is on mobile technology. The development in computer technology led to the emergence of mobile technology.

\section{Structure of Tablet computer}

The term tablet computer, or a tablet, is a mobile computer, larger than a mobile phone or Personal Digital Assistant (PDA), integrated into a flat touch screen and primarily operated by touching the screen rather than using a physical keyboard. It often uses an onscreen virtual keyboard, a passive stylus pen, or a digital pen. The standard form of tablet does not have an integrated keyboard but may be connected to one with a wireless link or a USB port.

\section{Multiple Functions of Tablet Computers in 2012:}

-Wireless mobile browser functions (using2G, 3G, 4G or Wi-Fi)

-E-mail and social media devices (typically with integration apps to bring all feeds into the same view)

-Potential cell phone functions (Messaging, video calling, speakerphone or headset cell phone uses)

-GPS satellite navigation Stills and video camera functions, photo and video viewing and editing

-E-book reading (including electronic versions of periodicals)

-Downloadable apps (games, education, utilities)

-Portable media player function, Weigh around one or two pounds (0.5 - 1 kilogram) Battery life of three to twelve hours depending on usage pattern.

-Flash memory solid-state storage drives and "instant on" warm-boot times; in addition, standard external USB and Bluetooth keyboards can often be used.

-Some have 3G mobile telephony capabilities

-A significant trait of tablet computers not based on the traditional PC architecture is that most mobile apps including third party ones are supplied through online distribution, rather than more traditional methods of boxed software or direct sales from software vendors.

\section{History of Tablet}

The tablet computer and the associated with pen computing technology, Electrical devices with data input and output on a flat information display have existed as early as 1888 with the telautograph. Throughout the 20th century it is created whether as blueprints, prototypes, or commercial products.

-Alan Kay attempted to formulate his Dynabook portable computer concept as early as 1968; with his 1972 paper: "A personal computer for children of all ages".

-In the 1994 the European Union initiated the 'OMI-NewsPAD' project (EP9252), requiring a consumer device be developed for the receipt and consumption of electronically delivered news / newspapers and associated multi-media. Space Odyssey. Acorn Computers developed and delivered an ARM based touch screen tablet computer for this program, branded the NewsPad. The device was supplied for the duration of the Barcelona based trial, which ended in 1997.

-Intel announced ARM based touch screen tablet computer in 1999, under the name Web PAD, the tablet was later re-branded as the "Intel Web Tablet".

-During the 2000s Microsoft attempted to define with the Microsoft Tablet PC the tablet personal computer product concept as a mobile computer for field work in business, though their devices failed to achieve widespread usage mainly due to price and usability problems that made them unsuitable outside of their limited intended purpose. 
In 2005, an internet tablet, the Nokia 770, was introduced. In 2005, an internet tablet, the Nokia 770, was introduced. This product line used the Maemo Linux operating system. Mobile operating systems have a different kind of interface than the traditional desktop OS, and represent a new type of computing device.

These "post-PC" mobile OS tablet computer devices are normally finger driven and most frequently use capacitive touch screens with multi-touch, unlike earlier stylus-driven resistive touch screen devices.

In April 2010 Apple Inc. released the iPad, a tablet computer with an emphasis on media consumption. The shift in purpose, together with increased usability, battery life, simplicity, lower weight and cost, As a result, two distinctly different types of tablet computing devices exist as of 2012, the Tablet PC and the Post$P C$ tablet, whose operating systems are of different origin.

Some professional-grade Tablet PCs use pressure sensitive films that additionally allow pressure sensitivity such as those on graphics tablets.

Concurrently capacitive touch-screens, which use finger tip detection can often detect the size of the touched area, and can make some conclusions to the pressure force used, for a similar result.

\section{Types of Tablets}

Tablet computers come in a range of sizes, currently ranging from tablet PCs to PDAs.

1)Slate tablet pc 2)Convertible tablet pc 3)Hybrid tablet pc 4)Booklets 5)Rugged tablet pc 6)Mini tablet 7)Phablet

\section{Features of tablet}

1) Lighter weight, lower power models can function similarly to dedicated E-book readers like the Amazon Kindle. Touch environment makes navigation easier than conventional use of keyboard and mouse or touch pad in certain contexts such as image manipulation, musical, or mouse oriented games and for people with certain disabilities.

2) Tablet PCs with digital pen are best for artists and graphic designers. Digital painting and image editing are more precise and intuitive than painting or sketching with a mouse.

3) The ability for easier or faster entry of diagrams, mathematical notations, and symbols

4) Allows, with the proper software, universal input, and independent from different keyboard localizations.

5) Tablets typically have longer battery life than laptops or note books.

6) The virtual keyboard is lit, thus more suitable to dark places.

\section{Tablet and Education:}

1. Classrooms \& Tablets: Though tablets are a recent phenomenon, many students in high school and college have been using smart phones for years, and are already well-acquainted with touch screen technology. Additionally, students - and consumers in general - are becoming more comfortable using tablets for advanced tasks like recording audio/video of class room lesson.

2. E-book and Tablets: E-book and tablets are cable of offering enhanced eBooks features like, it allows students to highlight text and take notes in the class room and access a dictionary directly within the book itself, and tablets are matching everything that a traditional book — print or digital — can offer.

3. Tablets Have the Software to Be Competitive: In addition to the thousands of exciting educational apps available, tablets are fully compatible with online teaching and learning platforms, such as Blackboard, which are becoming the norm at colleges and universities. In fact, tablets' current shortcoming — limited multitasking could be their greatest asset in education, as it forces students to focus on one task at a time.

4. Fit Students' Lifestyles \& Tablets: Tablets are thin, lightweight, and spring to life without delay, making them much easier to take to (and use in) class than a laptop or netbook. Longer battery life means that students don't have to worry about carrying a charger with them. Recording the lecture and replay it in just seconds helps to recall class lessons.

5. Tablets Integrate With Education IT Trends: Cloud-based solutions have become ever more popular with colleges and universities, which are looking to deliver synchronized experiences that, are device agnostic. With tablets and cloud-based systems, students can work anywhere on campus and make sure that their work is saved in a central location and accessible from all of their devices. They also don't have to pay for computing power that they no longer need.

6. Tablets Are Becoming More Available: One of the primary reasons that tablets have been slow to penetrate the higher education market was their limited availability. Apple's supply chain issues and the difficulty that 
some Android tablet manufacturers have faced in getting their products to market have made it difficult for schools to get serious about adopting. As these issues are resolved over the coming year, expect to see more and more tablets popping up on campuses.

Lower price points will make tablets even more appealing to colleges and universities. The wave of tablets introduced at CES in January is just the tip of the iceberg. With dozens to hundreds of offerings, many based on Google's open source Android OS, expect price points to fall quickly just as they have for laptops, smartphones and HDTV sets. How close are we today to tablets displacing computers on campuses?

Finally, the role of-ICT future learning should also be seen in the light of its contribution to emancipation, empowerment and to emancipation, empowerment and self-fulfillment. Learning objectives such as social competence, critical thinking and knowledge sharing and cooperation techniques will become more and more important as we move further into the knowledge society. It is estimated that tablet pe share will grow and soon surpass a popular netbooks.

Whether we like it or not, tablets are finding their way into education. Some think they are "expensive toys" or "books that glow". However, the reality is that teachers and, most importantly, students are increasingly finding them to be a useful addition to teaching and learning. The words may come from the students in future that, "I don't use paper for notes. I do everything on my iPad". With apps that do dictation or record conversations while you take notes for easy access later, the iPad is a great tool.

A child's favorite stories are easily found the e-reader apps, like Kindle for Android and each offering children's e-books with brilliant illustrations and playful features. Many e-books have a read-aloud function, following children to hear and see new words. The Popout! Tale of Peter Rabbit app even lets children control characters

Interactive games on a tablet's large, HD-quality screen, along with impressive sound quality, can help toddlers develop fine motor skills and correlate sound to vision. Games with bright, colorful graphics and fun noises make toddlers excited to play and learn. For example, in the game Peekaboo Barn, children open barn doors to find animals, learning about cause and effect and becoming familiar with animal names and sounds in English or Spanish. Another game, Number Hide and Seek, helps toddlers learn numbers and counting through a rhyming story.

Parents can stream educational television shows and movies from just about anywhere using apps like viewdini, a video portal that streamlines access to videos from a wide range of content providers. Games, stories and educational videos on a tablet are a great way to engage toddlers with technology that helps them learn and grow.

Tablet computers are a relatively new technology with a much different interface than previous computers. These elements are impossible to include in print or in a standard eBook. Read about music? Autoadvancing sheet music will appear as the audio plays. The results more integrated learning experience, which is more engaging for students. This isn't the future - this is today.

\section{The Use of Tablet Components in Education}

The use of tablet components may soon became an important part of learning strategies for teaching a wide range of subjects including physiology, although studies that have explored the educational impact of tablet more often focused on mathematics, engineering and computer science perhaps due to the more technical inkling of staff in these areas.

\section{Tablet Elements and Education}

Oral communication: Oral communication or lecture is an important example of a traditional mode teaching and learning. Traditional teaching method helps to transfer information (emotional and aesthetic) to hold the attention of students, to impress and to engage them. But in the new technology, major stored information can be used for lecture. There is human voice technology can be trained to project voice to an audience of 100-200 people or more. In built Microphone, amplifiers and other equipment can improve loudness and even quality of human speech.

Graphic Organizers: A graphic organizer is a pictorial representation of the relationships that exist between ideas. It shows how ideas are connected and how ideas are related to each other. It is the basis for all forms of comprehension. By definition, comprehension is an understanding of how ideas or concepts are assembled into groups.

Graphic organizers assist students in categorizing information. Most important, they help students understand the connections between their background knowledge and the knowledge they're learning in class. 
Visual components: Most lectures traditionally use black board or an overhead projector. Due to ICT, the speaker can combine pre-recorded images (including text) with images made during lecture. Prerecorded video fragments can be included accompanied by sounds if needed.

Image component: Images of real objects obtained via cameras can be downloaded to a tablet. This technology allows for clearer visualization, and saves time the lecture needs to spend on writing.

\section{Tablet resources are more effective in education?}

Many studies show that multimedia resources of tablet are more effective in enhancing quality of education. Because, the tablet resources helps to delivered the content in a variety of methods: as standalone internet-based applications, via a Wi-Fi or through a virtual learning environment (VLE). Resources may be used as a substitute for educational methods or used in a blended approach.

Quality in Teaching-learning: Teaching-learning and evaluation; teaching innovations; use of new media and methods; co-curricular activities; skill and competence development; projects and other avenues of learning; linkage with institutions, industries and commerce for teaching; linkage for field training; monitoring student progress; continuous internal assessment; use of external examiners; examination schedule, holding of examinations, evaluation, declaration of results; remedial and enrichment programs.

\section{Disadvantages of Tablet Computer}

Device dependency: The students have to depend upon particular device (their own tablet) to access saved information during examination time.

Reducing trend in reading and writing habits among students/teachers: In the conventional method of learning method, the student has to refer old books in the library to get the information on great personalities and other information. While searching in library, the students go through so many topics other than searching information. But in new technology the students will concentrate only on particular information and get it immediately. By this it may leads to reducing trend in reading and writing habits.

Dependency: Dependency on hardware engineers and regular electricity will more when a device is under repair and power fluctuation respectively.

Lack of concentration in the traditional class room: The new device will help in e-learning as well supplement to regular class room. Multimedia elements will assist the students to learn more effectively using online learning techniques irrespective of place and time. Due to this reason students will not concentrate to write notes in the conventional class room.

Enhancement of Absenteeism among students group: New technology will help to get ready notes and tutorials for the students to prepare projects as well for their examination. This will leads to increasing trends in absenteeism among students to the class. This will also leads to participate in politics and other anti-social activities.

\section{Conclusion}

With all disadvantages, the Impact of New technology in ICT (Information \& Communication Technologies) can help the students, researchers and academicians to access the full text from the electronic sources. Tablet computers are a relatively new technology in which, whether we like it or not, tablets are finding their way into education. Some think they are "expensive toys" or "books that glow". It may become boon for the future students for all ages - from the cradle to the grave. In reality is that teachers and, most importantly, students are increasingly finding them to be a useful addition to teaching and learning.

\section{References}

[1]. Brian X. Chen (2012-10-19). "How Are 7-Inch Tablets Doing?". The New York Times. Retrieved 2012-10-20.

[2]. Heater, Brian (2011-11-07). "Barnes \& Noble's Nook Tablet gets real, we go hands-on (video)". Engadget. Retrieved 2011-11-07.

[3]. Ziegler, Chris (2011-11-07). "Nook Tablet announced: \$249, available November 17th". The Verge. Retrieved 2011-11-07.

[4]. Barnes \& Noble (February 21, 2012). "Press Release - Barnes \& Noble Introduces NOOK Tablet ${ }^{\mathrm{TM}}$ - 8GB For Incredibly Low Price of \$199: New Addition to Hot-Selling, Highly Rated NOOK Tablet Line Offers Fastest, Lightest, Most Powerful Tablet with the Best in Reading and Entertainment, Now in 8GB, at an Amazing Value". Retrieved May 24, 2012.

[5]. "Nook Fires Back: Tablet \& E-Reader Family Aims At Amazon and More". Wired Magazine. 7 November 2011. Archived from the original on 7 November 2011. Retrieved 7 November 2011.

[6]. $\quad$ Barnes \& Noble. "NOOK Tablet Specs (16Gb \& 8Gb)".nookdeveloper.barnesandnoble.com. Retrieved June 7, 2012.

[7]. Liwen (January 30, 2012). "Easily Root Your Nook Tablet With An SD Card". xda-developers.com. Retrieved May 24, 2012. 
[8]. 8)Brad Linder, Editor (March 4, 2012). "Root tool for the 8GB NOOK Tablet now available".Liliputing.com. Retrieved May 24 , 2012.

[9]. Michael Crider (27 January 2012). "New Nook Tablet root method requires just a MicroSD card and a reboot". Retrieved May 24, 2012.

[10]. Eric Mack (December 22, 2011). "Electronics: How to Root the Nook Tablet". gizmag.com. Retrieved May $24,2012$.

[11]. -http://www.robaid.com/gadgets/nookcolor-is-a-logical-step-for-new-e-readers.htm

[12]. http://www.barnesandnoble.com/p/nook-tablet-barnes-noble/1104687969

[13]. http://bookclubs.barnesandnoble.com/t5/NOOK-Tablet-General-Discussion/Introducing-NOOK-Tablet-8GB/m-p/1295351\#M7447 